\title{
LAS SOCIEDADES PALEOHISPÁNICAS DEL ÁREA NO INDOEUROPEA Y LA ESCRITURA ${ }^{1}$
}

\author{
POR \\ JAVIER DE HOZ \\ Universidad Complutense. Madrid
}

\begin{abstract}
RESUMEN
Disponemos de poca información, pero se pueden establecer algunas hipótesis sobre el uso que de la escritura hicieron distintos grupos sociales en el área no indoeuropea de la Península. En el mundo tartesio la escritura alcanzó escasa difusión, y además la aristocracia no desarrolló usos simbólicos, a diferencia de otras aristocracias mediterráneas. El S.O. depende de las prácticas tartesias, pero innova al desarrollar una epigrafia sepulcral propia. El mundo ibérico presenta una gran complejidad; algunas áreas no van más allá que los tartesios, pero existe un estamento básicamente dedicado al comercio que desarrolla un uso activo y variado de la escritura.
\end{abstract}

\section{SUMMARY}

We have only few data, but it is possible to present some hypothesis about literacy of different social groups in non-Indoeuropean Hispania. Literacy is scarce in the Tartessian world, and the aristocracy did not create symbolic uses. The S.W. is similar, but there exist an original funerary epigraphy. The Iberian world is much more complex, and some regions and groups developed a very active and varied use of writing, particulary related to trade and other economic practices.

1 La primera versión de este texto correspondió a una conferencia en los cursos de la Universidad Complutense en El Escorial, durante el verano de 1990. Una versión más breve de algunas de las cuestiones aqui tratadas pero relativa también al área indoeuropea, en inglés, se publicará en "Paleohispanic Societies and Writing», II Coloquio internacional Arqueologia Hoje, Faro. La investigación en que se basan ambas publicaciones ha sido financiada por la Dirección General de Investigación Cientifica y Técnica (Proyectos PB87-0670 y PB90-0623). 
La historia de la escritura en la Península Ibérica en la antigüedad puede ser abordada desde muy diversos puntos de vista, desde los puramentes técnicos, como los recursos y los sistemas grafemáticos o los aspectos paleográficos, pasando por cuestiones epigráficas más o menos relacionadas con el contenido de los textos y su forma lingüistica, hasta problemas que llegan a inscribirse más bien en la historia de la cultura en sentido amplio, como pueden ser la función de la escritura en una sociedad dada y sus relaciones con la vida de esa sociedad en sus diversos aspectos, culturales, politicos, sociales y económicos. En lo que sigue voy a intentar dar un cuadro de las escrituras paleohispánicas desde estos puntos de vista citados en último lugar.

Pero antes de abordar el tema debo empezar por hacer dos observaciones previas. Para tratar adecuadamente las cuestiones que voy a suscitar es necesario tener resueltos previamente varios problemas de tipo más o menos técnico; en lo que sigue utilizaré, por lo tanto, los resultados de investigaciones anteriores que sería enojoso, e imposible por razones de tiempo, exponer aquí de forma adecuada, y que resumiré brevemente mencionando sólo en los términos más escuetos su grado de seguridad o su posición en el estado actual de las cuestiones. Además, y ésta es la segunda observación, debo advertir que la información de que disponemos por el momento para afrontar las cuestiones de que vamos a ocuparnos es muy insuficiente, a pesar de la continua publicación de descubrimientos significativos que contribuyen a su conocimiento, por lo que las conclusiones a las que he llegado deben ser consideradas fundamentalmente como hipótesis de trabajo racionalmente construidas sobre los datos disponibles en la Península lbérica y la comparación con lo que sabemos de cuestiones equivalentes en otras zonas del Mediterráneo antiguo, pero en modo alguno como resultados firmes y definitivos; valga esta advertencia previa para evitar en lo que sigue una reiterada y enfadosa sucesión de matizaciones y de expresiones de duda.

La escritura nació en la Península lbérica, de acuerdo con la generalidad de los investigadores, en el contexto de la cultura tartesia de la Baja Andalucía, en fechas dificilmente precisables pero que en todo caso no descienden del siglo vIl a. C. ya que para entonces existen testimonios materiales indiscutibles de su existencia ${ }^{2}$. Más problemático es su origen. Personalmente estoy convencido de que la primera escritura propiamente hispánica nació como adaptación de la escritura fenicia, es decir, como resultado de los contactos entre tartesios y mercaderes y colonos fenicios, que dieron lugar a la existencia de individuos bilingües y conocedores del alfabeto fenicio, alguno de los cuales tuvo la idea de realizar una adaptación de éste a las caracteristicas estructurales y fonéticas de la lengua tartesia, tal vez tomando en consideración secundariamente el alfabeto griego, en un momento en el que la sociedad tartasia estaba madura para asumir la nueva técnica, hacerla suya y transmitirla a las generaciones sucesivas ${ }^{3}$.

${ }^{2}$ Los grafitos de Huelva, a los que luego me referiré, y, según me comunica M. Almagro Gorbea, una lápida de Medellin. Los grafitos son un testimonio indiscutible para Correa y para mí, y para la generalidad de los arqueólogos que se han ocupado de ellos - Almagro-Gorbea, Bendala, Jurado, etc.-, pero J. Untermann prefiere considerarlos escritura fenicia (MLH III 1, 123 n. 82) y en todo caso niega su valor para el conocimiento de la historia de las escrituras hispánicas (MLH III I, 96, n. 19 y 136 n. 18 ).

${ }^{3}$ Existen sin embargo otras alternativas defendidas en la bibliografia antigua y reciente. La postura de J. A. Correa y la mía se van aproximando (Correa, 1989: «El origen»; 1993: «El signario de Espanca»), pero no asi la de Untermann (MLH III 1, 135-6). 
No entraré en los problemas técnicos de la adaptación, que son particularmente complejos, más de lo habitual en esos procesos, y que ya he discutido en otras ocasiones a la vez que justificaba mi teoria sobre el origen de las escrituras hispánicas ${ }^{4}$, pero si conviene indicar que ya desde entonces apareció, al menos en embrión, el rasgo distintivo de casi todas las escrituras indigenas utilizadas en la Peninsula Ibérica en la antigüedad, que nos permite considerarlas como una única familia, ligada por relaciones genéticas entre sus diversos miembros; se trata de su caracter mixto, en parte silábico, en parte alfabético, es decir, la peculiaridad de que una parte de sus signos, los que representan vocales y consonantes no oclusivas, son letras del mismo tipo que las de nuestro alfabeto, mientras que los fonemas oclusivos no tienen representación gráfica autónoma sino que se expresan siempre por medio de grafemas silábicos, en los que la oclusiva va acompañada de una vocal. Esta peculiaridad exige que para representar una determinada oclusiva existan tantos signos como vocales posee la lengua en cuestión, y por supuesto implica que cada vocal sea representada por un signo alfabético cuando no va precedida por una oclusiva, y en caso contrario por un signo silábico diferente, según la oclusiva que preceda; por ejemplo, existirá un grafema $a$ y otros de valor $b a, t a$ y $k a$; no existirá un signo $t$, pero existirán $t a, t e, t i, t o$ y $t u^{5}$.

Los ejemplos que acabo de citar ilustran otra particularidad de las escrituras paleohispánicas; las transcripciones $b a, t a$ y $k a$ son convencionales, pues, de hecho, la escritura no distingue entre sordas y sonoras a pesar de que algunas de las lenguas que se expresaron por medio de ella, como el ibérico y el celtibérico, sí poseian esa distinción fonológica. Probablemente hay que ver aqui un rasgo característico de la lengua para cuya transcripción se creó la primera escritura paleohispánica, es decir, de la lengua tartesia, transmitido luego por el peso de los sucesivos modelos a las restantes escrituras paleohispánicas ${ }^{6}$.

Estos rasgos característicos que acabo de mencionar, a los que se podrian añadir otros aunque quizá no tan significativos, son ajenos a la escritura fenicia, y también al alfabeto griego, que según algunos autores pudo jugar también el papel de modelo de la primera escritura paleohispánica, e implican, por lo tanto, que el proceso de creación de ésta no fue un simple remedo ocasional de los usos de los colonos y mercaderes foráneos, sino una labor compleja y estudiada, posiblemente con motivaciones profundas, y realizada con una idea relativamente clara de las funciones que iba a desempeñar la nueva técnica en el mundo tartésico. Es decir lo que ya previamente habia mencionado, que la sociedad tartésica estaba madura para asumir la escritura.

El problema que se plantea en este punto es el de intentar describir en qué forma utilizaron los tartesios la escritura, qué rasgos de su estructura social o cuáles entre sus actividades les

${ }^{4}$ de Hoz, 1985: «El origen de la escritura»; 1990: «El origen oriental»; 1991: «The Phoenician origin»".

" de Hoz, 1983: "Origine ed evoluzione», 27-28; Untermann: MLH III 1, 134-136.

- El problema de la ausencia de notación de las oposiciones de sonoridad es bastante complejo y no puedo entrar aquí en detalles; en teoría no sería imposible que se prescindiese de ella por razones de economia de grafemas, pero la dependencia de un sistema concebido para una lengua en que no existia tal oposición fonológica es segura en el caso de las lenguas indoeuropeas de Italia de notación deficitaria en ese aspecto - dependientes del etrusco-, y sin ser segura es la hipótesis más probable para el silabario micénico. Por otro lado, puesto que la oposición existía sin duda en el modelo o modelos de la primera escritura paleohispánica, resulta inverosimil que los creadores de ésta hubiesen prescindido de esa oposición si se daba también en su propio sistema fonológico. 
hicieron sentir la conveniencia de procurarse una téenica propia comparable a la que observaban en uso entre los fenicios. y cómo evolucionó su actitud hacia la escritura a medida que ésta les fue resultando más familiar. Son cuestiones excesivamente complejas para la parquedad de nuestros datos, pero si a éstos unimos lo que sabemos de procesos similares en otras sociedades, es posible por lo menos delimitar una respuesta.

El punto de partida está naturalmente en los testimonios director que del uso de la escritura tenemos en el área tartésica, en especial en las fechas que corresponden a la cultura así llamada. $y$ que podemos considerar concluida en el siglo $\mathrm{V}$, cuando se han producido cambios lo suficientemente significativos como para que hablemos de un mundo turdetano, continuador pero distinto del tartesio?

La primera dificultad estriba en que en esas fechas altas en Andalucia prácticamente no existen testimonios epigráficos de cronologia segura; tan sólo podemos citar los grafitos sobre cerámica de Huelva, los más antiguos de los cuales remontan al menos al siglo VII, y que constituyen la prueba directa de que los tartesios conocian la escritura ${ }^{x}$. Los grafitos del Carambolo, en los alrededores de Sevilla, aunque son también de cronología tartésica no pueden ser utilizados como testimonio, porque en ningún caso existe la certeza de que se trate de escritura y no de simples marcas".

La generalidad de los autores suele referirse, sin embargo, a otros epigrafes cuando habla de epigrafia tartesia. Existe, en efecto, un conjunto epigráfico muy bien definido a la vez por sus características materiales y grafemáticas, que penetra en la Andalucía occidental, aunque su área propia se encuentra en el Sur de Portugal; se trata de lápidas sepulcrales escritas en la escritura paleohispánica que, para no prejuzgar conclusiones, puede ser llamada del S.O., aunque a menudo se denomine tartesia, y en una lengua que por el momento nos resulta casi totalmente criptica ${ }^{10}$. De estas inscripciones una ha aparecido en la provincia de Córdoba y dos en la de Sevilla ", y aunque ninguna de las publicadas puede ser fechada con seguridad, en el territorio portugués se relacionan claramente con un conjunto de necrópolis que definen una cultura contemporánea de la tartesia y claramente influida por ésta. Por ello una opinión bastante difundida ve en estas inscripciones un rasgo de la cultura tartesia que habria penetrado en su periferia portuguesa y extremeña, junto con otras influencias muy visibles, y que sólo por azar estaria mucho peor documentada en Andalucia que en Portugal.

Por mi parte, hace tiempo que defiendo el caracter secundario de la escritura del S.O., basándome en argumentos puramente grafemáticos que exigen, a mi modo de ver, postular la existencia de un modelo intermedio entre la escritura fenicia y la del S.O., que podría identificarse o no con la escritura atestiguada en la Andalucía oriental y el S.E. ${ }^{12}$. A estos argumentos han venido a añadirse recientemente un testimonio importante; en pleno territorio de la

7 Sobre este aspecto de la periodización andaluza Pellicer, M., 1979-1980: «Ensayo», Escacena, J. L., 1989: «Los turdetanos», 439-450.

" de Hoz, J., 1976: «La epigrafia prelatina», 270-282; Fernández Jurado, J. \& Correa, J. A., 19881989: «Nuevos grafitos».

" de Hoz, J., 1976: «La epigrafía prelatina», 282-284.

${ }^{10}$ Correa, 1985: "Consideraciones»; 1992: "La epigrafia tartesia»; de Hoz, 1989: «El desarrollo.»

${ }^{11}$ Gómez-Moreno, 1962: Escritura bástulo-turdetana, núm. 30; Correa, 1985: La inscripción; 1978: «Inscripción tartesia».

12 de Hoz, 1985: «El origen de la escritura», 460-462. 
epigrafia portuguesa del S.O., en Espanca, cerca de Castro Verde, ha aparecido un documento excepcional y único por ahora en la Peninsula lbérica. aunque existen en otras zonas del Mediterráneo y del Próximo Oriente ${ }^{\text {í }}$. Se trata de un ejercicio de aprendizaje; sobre una laja de pizarra un maestro ha grabado la secuencia de los signos de una escritura palcohispanica, y en una linea inferior el discipulo los ha repetido con mano insegura. Lo importante es que el signario de Espanca presenta, junto a claros indicios de su origen en el alfabeto fenicio, discrepancias caracteristicas con respecto al conjunto de signos de la escritura del S.O. que, a juzgar por lo que conocemos en casos paralelos, como los alfabetarios utilizados en la enseñanza de la escritura etrusca, tienen una explicación simple; el caracter acusadamente tradicional de la enseñanza dio lugar a que se transmitiese un signario teórico, idéntico al de la escritura modelo, aunque en la práctica no se utilizaba la totalidad de los signos asi aprendidos.

El signario de Espanca testimonia la existencia de una escritura modelo de la del S.O., pero algo más compleja, y por razones históricas esa escritura no puede ser sino la tartesia. Junto al testimonio de los grafitos de Huelva podemos colocar, por lo tanto, otros testimonios que no por ser indirectos resultan menos probatorios, el signario de Espanca como signario tartesio aunque usado por gentes del S.O., y la epigrafia misma del S.O., contemporánea de la cultura tartesia y que, dada su pertenencia a la familia de escrituras paleohispánicas, de origen evidentemente único, y dadas las relaciones mediatas y no profundas del Sur de Portugal y Extremadura con el mundo colonial, debe explicarse por el modelo de la escritura tartesia ${ }^{14}$.

Sin embargo, a pesar de que la verosimilitud histórica aconseje situar en el mundo tartésico los orígenes de las escrituras paleohispánicas, y de que existan testimonios directos e indirectos de la escritura tartesia, en cuanto intentamos precisar los aspectos no meramente técnicos de su creación y hacernos una idea del papel que ha jugado en la sociedad tartesia, advertimos que las lagunas de nuestra información son excesivas y que desconocemos datos esenciales. De ahi la importancia de tomar en consideración, como ya he mencionado, procesos similares de sociedades mejor conocidas.

Las escrituras antiguas del Mediterráneo, nacidas de un préstamo bien documentado, que conocemos mejor son la griega, la etrusca y la latina. En todos esos casos, y también en otros peor conocidos, puede afirmarse que la escritura aparece en un momento en que las actividades económicas, singularmente el comercio, estản en plena expansión, y que los portadores de la escritura modelo participan activamente en esas actividades comerciales ${ }^{15}$. Es cierto que la historia posterior conocerá reiteradamente la creación de una escritura por razones puramente

${ }^{13}$ Correa, 1993: «El signario de Espanca»; en prensa: «El signario hallado»; de Hoz, 1990: «El origen oriental»; 1991: "The Phoenician origin»; Untermann, en prensa: "La escritura tartesia».

is Sobre la cultura del S.O. en Portugal no existe de momento ningún trabajo suficientemente extenso; puede consultarse Varela Gomes en da Silva, A. C. F. \& Gomes, M. V., 1992: Proto-Historia, 103-164, y Beirâo, C. M. de Mello, 1986: Une civilisation. Para Extremadura Almagro-Gorbea, M., 1977: El Bronce Final, y 1990: «El periodo orientalizante en Extremadura»; Enriquez, J. J., 1990: «El Bronce final extremeñom.

is Varios trabajos significativos en Phoinikeia Grammata, 1991; Harris, W. V., 1989: Ancient Literacy, 45 y 149, aun reconociendo el papel del comercio, peca de superficial. Para el alfabeto griego es básico Heubeck, A., 1979: Schrift, 75-100; vid. también de Hoz, 1983: «Algunas consideraciones», y para la bibliografia más reciente Isserlin, B. S. J., en Phoinikeia Grammata cit. Para Italia sigue siendo básico Cristofani, M., 1972: «Sull’origine»; bibliografia posterior en el artículo de Briquel, D., en Phoinikeia Grammata cit. Problemas paralelos en Lejeune, M., 1983: «Rencontres». 
culturales, en concreto religiosas, cuando los misioneros de alguna de las grandes religiones proselitistas pongan a punto una grafia para poder traducir sus libros sagrados a una lengua hasta entonces no escrita, pero este fenómeno todavia no se daba en esas fechas ${ }^{16}$. Aún así puede proporcionarnos también algún paralelo útil, sobre todo si tomamos en cuenta un aspecto esencial en la historia de las escrituras que es el de su transmisión. En el caso de estas escrituras proselitistas, y antes de que se produzca su frecuente expansión a otras esferas de uso, que puede traer consigo una generalización dentro de la sociedad receptora al margen de los limites de los meros conversos, la escritura se transmite a través de una escuela confesional en la que, aun cuando los maestros sean ya nativos, pertenecen a los miembros activos de un grupo religioso ${ }^{17}$; es decir, y éste es el dato más generalizable, que puede existir dentro de una sociedad una transmisión de la escritura limitada a uno o varios grupos definidos por una actividad concreta, y que no alcanza, por lo tanto, a la generalidad de esa sociedad, ni siquiera en sus capas superiores. Es un fenómeno bien conocido en el caso de las culturas que han desarrollado escrituras de extraordinaria complicación, cuyo uso quedaba reservado a un pequeño núcleo de escribas especialistas, sometidos a un entrenamiento largo y riguroso, como fue el caso de Mesopotamia o Egipto en la antigüedad ${ }^{1 x}$, pero en condiciones sociales adecuadas puede darse también con sistemas de escritura perfectamente simples; baste pensar en el caso del alfabeto latino en amplios períodos de la historia europea medieval ${ }^{19}$.

Pero volviendo a los casos mencionados, y aunque existan aún ciertas discrepancias en la interpretación de sus respectivos procesos históricos, creo que puede admitirse que tanto el alfabeto griego como el etrusco y el latino nacieron como consecuencia de la intensificación de la actividad comercial y económica en general, y que en ellos se dieron también otras circunstancias que se repiten en la cultura tartesia de forma más o menos próxima.

Por ello hay ciertos aspectos del proceso de creación de la escritura tartesia que pueden parecer claros a la luz de las analogías mencionadas. La escritura tartesia nace en el momento de mayor intensidad del fenómeno orientalizante en el mediodia peninsular, a la vez que la influencia cultural y técnica de los fenicios se deja sentir con fuerza creciente en otros aspectos de la civilización tartesia ${ }^{20}$. En el mundo tartesio, como en el etrusco o el griego del siglo VIII, existe una aristocracia que asimila en grado muy superior al de los otros estratos sociales esas influencias, y las adapta en una creación original ${ }^{21}$. Esa aristocracia controla los recursos naturales que buscan los fenicios, y participa de un sistema de intercambios que va más allá

16 Dejo de lado otro fenómeno también anacrónico para la sociedad tartesia, el de la creación, o adaptación, «nacionalista» de una escritura, para defenderse de influencias culturales extrañas y revalidar la propia tradición sin renunciar a modernizarse; vid., por ejemplo, Lewis, I., 1986: «Literacy».

17 Por ejemplo, las escuelas coránicas y las misionales.

${ }^{18}$ Mejor que en el intento de presentación general, demasiado vago, de Goody, J., 1986: La logique, se debe acudir a la bibliografia de primera mano, por ejemplo, al capítulo $\mathrm{V}$ de la siempre espléndida Oppenheim, A. L., 1964: Ancient Mesopotamia.

${ }_{19}$ Muchos datos en los diversos articulos de McKitterick, R., ed., 1990: The uses.

${ }^{20}$ Parto de la base de que los grafitos tartesios arriba mencionados, y la repercusión de la escritura tartesia en el S.O., son suficiente demostración de su existencia al menos ya en el siglo vII, a pesar de las dudas de algunos colegas. La bibliografia sobre la influencia fenicia en el mundo tartesio se confunde prácticamente con la bibliografia general sobre éste; vid., por ejemplo, Aubet, M. ${ }^{a}$ E., ed., 1989: Tartessos; 1977-1978: "Algunas cuestiones»; Almagro, 1991: «El mundo orientalizante»; Bendala, 1990: «Tartessos hoy».

${ }^{21}$ Aubet, 1984: «La aristocracia». 
del originado por los mercaderes orientales. La actividad económica en general experimenta una aceleración evidente. Todos estos rasgos, más o menos matizados, son comunes a las culturas proto-históricas que han tomado en préstamo una escritura, y es lógico buscar en ellos los motivos que justifican el desarrollo de la nueva técnica.

Pero si desde el punto de vista de las motivaciones, el desarrollo de la escritura tartesia puede ser comparado con el de otras escrituras mediterráneas antiguas, hay otros aspectos que resultan por ahora mucho más dudosos. Griegos y etruscos desarrollan rápidamente usos complementarios de la escritura que son distintos porque también lo son ambas sociedades, pero que tienen elementos comunes que se dan ya en la escritura modelo fenicia y que en algunos casos, en especial las inscripciones de propiedad en su forma más simple, resultan obvios y casi inevitables. En el mundo tartesio, hasta la fecha no advertimos prácticamente esos usos complementarios, e incluso los grafitos de propiedad están mínimamente atestiguados. Naturalmente aquí se plantea ante todo una cuestión circunstancial, la de hasta qué punto está suficientemente explorada desde el punto de vista arqueológico la cultura tartesia como para que podamos responder adecuadamente a ciertos problemas y, sobre todo, sacar conclusiones de la ausencia de ciertos documentos. Indudablemente, y a pesar del enorme esfuerzo y progreso de los últimos tiempos, la cultura tartesia sigue estando muy mal conocida ${ }^{22}$, son pocos los yacimientos excavados y ninguna en una extensión realmente significativa, y se desconocen casi del todo las necrópolis indigenas, que en el caso de otras culturas han proporcionado importante información epigráfica; mas aún, no existe un solo caso de santuario tartesio conocido, con la excepción del Santuario de la Algaida que tiene un caracter más bien marinero e internacional ${ }^{23}$. Cabría pensar, por lo tanto, que simplemente falta aún investigación arqueológica para que podamos hacernos una idea de la utilización de la escritura tartesia sobre materiales duraderos, pero hay ciertos indicios de que en cualquier caso esa utilización no debió ser muy abundante.

Es significativo el contraste con la epigrafia colonial en la propia área tartesia, que en principio debiera sufrir de las mismas limitaciones de la documentación, y que por ser un elemento extraño, sólo ocasionalmente justificado en el contexto nativo, se esperaría que hubiese dejado menos testimonios que la escritura local. Sin embargo, poseemos una inscripción votiva fenicia arcaica de los alrededores de Sevilla sobre una pequeña estatua de bronce que representa a Astarté, a quien está dedicada la inscripción ${ }^{24}$, y en Huelva, en la zona portuaria antigua, han aparecido un par de grafitos griegos, uno de los cuales al menos presenta indicios de haber sido grabado ya en relación con el mundo indigena ${ }^{25}$. Evidentemente se trata de un material muy escaso y, por lo tanto, no puede en modo alguno desecharse la acción del azar, pero puede tratarse también de un primer indicio significativo.

Existe otro, a mi modo de ver más pertinente, que viene dado por los que podemos considerar como monumentos funerarios propiamente tartesios ${ }^{26}$. Ya he indicado que la informa-

22 Bendala, 1990: «Tartessos hoy», 14.

23 Blanco, A. \& Corzo, R., 1983 julio: «Monte Algaida».

${ }^{24}$ La bibliografía es abundante, vid,, por ejemplo, Gibson, J. C. L., 1982: Textbook, 64-6, con referencias anteriores.

${ }^{25}$ Fernández Jurado, J., 1984: La presencia griega; Fernández Jurado, J. \& Olmos, R., 1985: «Una inscripción».

26 Bendala, 1992: "La problemática»; Pellicer, 1993: "Crítica analítica», 195-196 y 202-204; Ruiz Delgado, M. M., 1989: «Las necrópolis tartésicas». 
ción de este tipo es muy escasa, a lo que se añade en los últimos tiempos una cierta tendencia a reinterpretar como testimonios de colonias de agricultores orientales algunas de las necrópolis hasta ahora consideradas tartesias, como la de La Cruz del Negro, cuestión ésta no suficientemente aclarada todavia aunque a mi modo de ver poco verosimil ${ }^{27}$, pero en cualquier caso subsisten ciertos grupos de tumbas en las que debemos ver enterramientos de la aristocracia tartesia del momento de máxima influencia orientalizante, en Huelva, Carmona y Setefilla. Estas tumbas presentan los rasgos característicos de los enterramientos aristocráticos en otras zonas del Mediterráneo en las que una élite social ha podido controlar el comercio de larga distancia y ha acumulado sus beneficios, invirtiéndolos al menos en parte en bienes de prestigio que contribuian a la afirmación y el mantenimiento de su poder en el ámbito local. Si la aristocracia tartésica hubiese desarrollado formas no puramente prácticas, o al menos con un cierto contenido ceremonial, del uso de la escritura, sería de esperar que al menos algún indicio hubiese quedado en el contenido de esas tumbas, de la misma forma que lo encontramos en las tumbas etruscas ${ }^{2 x}$. El argumento tiene, sin embargo, la debilidad de todos los argumentos negativos, aumentada en este caso por las limitaciones de nuestro conocimiento de la cultura tartesia, sobre las que ya he insistido, y no se puede excluir la posibilidad de que hallazgos futuros modifiquen sensiblemente nuestra imagen del uso de la escritura entre los tartesios.

Pero ateniéndonos por el momento a los datos de que disponemos, merece la pena plantearse si a partir de ellos podemos llegar a obtener una imagen coherente de lo que fue el proceso de adopción de la escritura en el mundo tartésico y su evolución posterior.

Insisto una vez más en que el préstamo debe explicarse en el contexto del conjunto de intercambios económicos entre los colonos y mercaderes orientales y los indigenas. Esos intercambios tuvieron que dar lugar a la existencia de individuos bilingües pertenecientes a los grupos especializados en ellos, y en un paso más adelante debieron familiarizar a algunos de esos indigenas bilingües con las prácticas escritas de los orientales. No creo que bastase con la observación superficial de que en las colonias o factorías fenicias existían lápidas sepulcrales inscritas, o de que ciertos objetos de uso eran portadores de inscripciones. La imitación de estas prácticas pudo, desde luego, darse en un momento posterior, pero el punto de partida tuvo que ser otro porque si no no me parece justificado el esfuerzo social que se puso en marcha.

Hay que partir, en efecto de que el creador o creadores de la escritura tartesia, indigenas o fenicios pero en cualquier caso bilingües, consiguieron introducir una nueva técnica que exigía un aprendizaje, por simple que éste pueda parecernos en contraste con el de otros sistemas orientales de escritura. Ese aprendizaje es por supuesto un hecho social que afecta a la transmisión de la tradición de unas generaciones a otras, pero no a la transmisión asumida de forma prácticamente inconsciente en los hábitos sociales, sino a la que exige una organización y una técnica, y no se explica sin una demanda de cierta amplitud, aunque sea exclusiva de un grupo dado.

No se puede rechazar a priori, aunque no parece nada probable, el que un amplio conjunto de la sociedad tartesia sintiese la atracción de la escritura como una forma más de expresión

27 Vid., por ejemplo, la polémica en Congreso de arqueología ibérica, 676-681.

${ }^{26}$ Vid., por ejemplo, G. Camporeale en Civilità degli etruschi, 1985, 79 y las piezas 3.6-8 y 3.14.17 del catálogo. 
orientalizante, y que por lo tanto los creadores de aquélla encontrasen ya creado un ámbito de desarrollo y transmisión de su nueva técnica: tampoco cabe rechazar a priori, aunque depende de una idea de la sociedad tartesia que está muy lejos de haber sido probada, que una autoridad superior, con los medios disponibles para asegurar la continuidad del proceso, desease disponer de la escritura como un medio más de prestigio.

Pero dejando a un lado la total falta de indicios en ambos casos, y la escasa probabilidad de ambos, sobre todo el primero, en términos históricos, existen contra ellos argumentos concretos. El fenómeno orientalizante en la sociedad tartesia parece haber tenido limitaciones importantes y no haber llegado nunca a eliminar formas tradicionales de cultura; parece totalmente inverosímil que una sociedad que permanecía aferrada a sus tradiciones de cerámica fabricada a mano sintiese la necesidad de una expresión ceremonial orientalizante tan sofisticada como la escritura. Claro está que este argumento no tiene validez si imaginamos esa necesidad en un ámbito muy restringido ${ }^{29}$, el de una aristocracia minoritaria o incluso el de una supuesta realeza con control de un amplio territorio; existe, sin embargo, otro argumento que si afecta a esta segunda hipótesis.

En efecto, si partimos de la idea de motivaciones ceremoniales y de prestigio en el desarrollo de la escritura, tenemos que aceptar que su uso debió de ser fundamentalmente público y visible, lo que casi obligadamente nos lleva a suponer la existencia de soportes de cierta entidad y duraderos, es decir, al tipo de testimonios escrituarios cuya falta precisamente se hace sentir de forma tan acusada en el registro arqueológico tartésico hasta la fecha.

Por lo tanto, y sin excluir que hallazgos futuros obliguen a revisar estas ideas, me inclino a pensar que la aparición de la escritura en el mundo tartesio se debió a razones puramente prácticas y técnicas en la esfera limitada de las gentes directamente implicadas en los intercambios comerciales con los orientales. Naturalmente debía existir una vinculación estrecha entre esas gentes y la aristocracia tartesia, si aceptamos que ésta ejercía el control último de esos intercambios, y esa vinculación podria haber dado lugar, como ocurrió en el caso etrusco, a que la aristocracia tartesia asumiese la escritura como una más de sus formas de expresión, a través de las que se definía y se diferenciaba del resto de la sociedad, y mantenía su prestigio, pero ello no fue así al parecer.

Conviene subrayar que no existe ninguna necesidad histórica incontrovertible en los procesos de préstamo cultural, incluso en casos relativamente similares en sus condiciones generales. Los príncipes célticos de la Europa hallstáttica se beneficiaron de un intenso comercio a larga distancia sin llegar a adoptar la escritura que desde luego era bien conocida en el mundo griego o etrusco de sus proveedore ${ }^{30}$, y cuya utilización técnica se manifiesta incluso en trabajos que debieron realizarse en el propio territorio céltico, como el montaje de la crátera de Vix, siguiendo las pautas dadas por los signos alfabéticos de las piezas ${ }^{31}$. Y la historia del comercio medieval y moderno en Africa proporciona ejemplos de reacciones diferentes ante estímulos similares. No debe sorprendernos por ello que la sociedad tartesia se comportase

${ }^{29}$ Cf. más adelante sobre la escritura del S.O.

${ }^{30}$ El testimonio más antiguo de escritura al N. de los Alpes, todavía tan mal comprendido que no es ni siquiera clasificable, lo encontramos en un fragmento de tablilla de Dürrnberg: Zeller, K. W., 1988: «Neue keltischer Gewerbebauten», 11 y 13. Para testimonios posteriores vid. Jacobi, G., 1974: «Zum Schriftgebrauch»; Krämer, W., 1982: «Graffiti».

31 Jeffery, L. H., 1990: The Local Scripts, 191-192 y 375. 
de modo peculiar, y no supiese o quisiese desarrollar la escritura en el grado en que lo hicieron los etruscos del siglo VII o los griegos del VIII - por supuesto en fechas posteriores la evolución de los griegos y etruscos quita todo sentido a su utilización como paralelo histórico de los tartesios.

Pero es probable que la actitud inhibida que parece haber predominado en la sociedad tartesia frente a la escritura tuviese también causas definidas en su propia estructura y desarrollo. Parece claro que la aparición de una sociedad propiamente urbana favorece la ampliación de las prácticas escritas, tanto en el número de los implicados como en su propia variedad interna ${ }^{32}$, lo que a su vez provoca una mayor abundancia de testimonios susceptibles de pervivir y de llegar a ser estudiados algún dia. Desde este punto de vista sería deseable tener una idea más clara de hasta qué punto llegaron los tartesios en su desarrollo urbano, pero la información de que por el momento se dispone no anima a ser particularmente optimistas. Algunos expertos en el tema rehusan decididamente atribuir el desarrollo propiamente urbano de la Andalucía antigua a la evolución interna de la cultura tartésica ${ }^{33}, y$, en general, se prefiere hablar de una sociedad protourbana. El problema estriba naturalmente en establecer matices y grados en esa definición muy general, pero probablemente ese estadio protourbano no había alcanzado el mismo nivel de desarrollo que el que se daba en Italia en momentos para los que también se puede utilizar la calificación de protourbanos y en los que, sin embargo, el uso de la escritura aparece diversificado y extendido ${ }^{34}$.

En todo caso los datos de que disponemos hasta el momento indican claramente que la escritura está intimamente ligada al fenómeno orientalizante, $\mathrm{y}$ a falta de indicios en otro sentido creo que debemos valorar en primer lugar los aspectos económicos de ese fenómeno. La escritura tartesia es una técnica orientalizante que se justifica en la conveniencia de los responsables directos del comercio tartesio y, tal vez, de la explotación de recursos en escala mayor, al menos mayor desde la óptica de magnitudes del mundo tartesio, como debió darse en el caso de la minería; esos responsables constituían una fracción minoritaria de la sociedad taresia que dependía de, o en parte se confundía con, la aristocracia tartesia. Lo limitado de su número, junto con la falta de interés de esa aristocracia por los aspectos ceremoniales y simbólicos de la escritura, explica el que ésta no llegase a tener una variedad de funciones y, por lo tanto, un peso cuantitativo, en los hábitos culturales tartesios. En cuanto a la sociedad turdetana, heredera de la tartesia desde aproximadamente comienzos del siglo $\mathrm{V}^{35}$, los escasos indicios que poseemos, y que en general proceden de las zonas próximas al territorio de los iberos oretanos, parecen indicar que ha mantenido tradiciones similares a las de los tartesios en lo que al uso de la escritura se refiere ${ }^{36}$.

Las observaciones previas implican una definición restrictiva de lo que podemos llamar epigrafia tartesia, y que es la que he justificado en páginas previas. Según esa definición debemos considerar la epigrafia del S.O., representada en su casi totalidad por lápidas sepul-

32 Incluso la exige según algunos autores como, por ejemplo, Coulmas, F., 1989: The Writing Systems, 7-8, que cita en su apoyo un clásico, Childe, G., $1982(=1942)$ : What Happened, 31 y 98.

${ }_{33}$ Aubet, 1977-1978: "Algunas cuestiones», 99-100, 107; Bendala, M., 1989: "La génesis», 135.

34 Torelli, M., 1990 (= 1981): Storia, 105-112.

${ }^{35}$ Cf. supra n. 7.

${ }^{36}$ de Hoz, 1989: «El desarrollo», 554-558; Untermann, MLH III, 2, 637-660. Añadir Morena, J. A., 1989: El santuario, 64. 
crales $^{37}$, como testimonio de una escritura y una lengua no tartesias, aunque contemporáneas al menos en parte de la cultura tartesia y atestiguadas en algunos casos en el territorio de ésta ${ }^{3 x}$. Todo ello exige una explicación compatible con los modelos utilizados hasta el momento para interpretar el desarrollo de la escritura tartesia.

Como ya he dicho, tanto razones internas como el testimonio del signario de Espanca indican que la escritura del S.O. es una adaptación de la tartesia, su origen debemos buscarlo pues en la existencia de gentes bilingües, hablantes a la vez de la lengua tartesia y de la del S.O. y conocedores de la escritura tartesia; no es necesario, por el contrario, contar con una influencia fenicia directa. Desde el momento en que existen inscripciones del S.O. tanto en territorio tartesio como fuera de él, la cuestión de la zona de origen de la escritura del S.O. no resulta obvia, y deberá ser afrontada también a la vez que la de las condiciones del contacto que expliquen la existencia de esas gentes bilingües que hemos mencionado, y la del contexto histórico en que ese contacto haya podido provocar la aparición de una demanda de escritura en la sociedad del S.O. Todo ello exige recapitular brevemente lo que sabemos de esa sociedad.

La continuidad de la Edad del Bronce es más acusada en el territorio extremeño y del Sur de Portugal durante el período orientalizante que en la Baja Andalucía. En ambas zonas perdura una tradición de enterramientos en cistas, y es característico el empleo de losas sepulcrales decoradas, que en la versión portuguesa más antigua - losas decoradas con armas en relieveremonta al Bronce Medio. Tanto las losas como otros aspectos del testimonio arqueológico no exclusivos del ritual funerario parecen indicar que el proceso de diferenciación social, y la aparición de una aristocracia con considerable capacidad de tesaurización, era relativamente antiguo y quizá explicable sin recurrir a estímulos exteriores, sino dentro del proceso interno de la propia sociedad del S.O. ${ }^{39}$ Los estímulos externos no faltan, sin embargo; sobre todo procedentes del área atlántica, en particular desde el centro de Portugal, y del área tartesia. Estos influjos tartesios van acompañados de elementos orientalizantes que en parte pueden haber sido introducidos desde las costas portuguesas por los fenicios, pero que sobre todo deben haber sido aportados por los propios tartesios ${ }^{40}$.

Hay que tener en cuenta en este sentido sobre todo los recursos mineros de esas zonas del S.O., que explican la atracción que han podido ejercer para los tartesios en su papel de intermediarios mercantiles de los fenicios. La relación entre tartesios y aristocracias locales debió dar lugar a relaciones y procesos en parte similares a los que habia originado el contacto entre tartesios y fenicios, en especial el incremento de la actividad económica y el control de la riqueza originada por una élite social que empleó en parte esa riqueza en bienes de prestigio, pero debieron existir diferencias de cierta importancia entre ambos casos. Los tartesios parecen haber desempeñado un papel comercial mucho más activo, son claros sus intereses mariti-

${ }^{37}$ A falta de un corpus propiamente dicho, el repertorio más completo se encontrará en Beirâo, C. M. de Mello, 1986: Une civilisation, 125-146.

38 Vid. n. 11 y añadir Otero, J. M. \& Melena, J. L., 1976: «La estela»; Berrocal, L., 1987: «La losa de Capote».

39 Almagro-Gorbea, 1992: «Las necrópolis ibéricas», 40.

40 La influencia fenicia es la más valorada, por ejemplo, por Gomes en da Silva, A. C. F. \& Gomes, M. V., 1992: Proto-historia, 133-136. En general, la mayor parte de los arqueólogos pone el énfasis en la influencia tartesia, y, a mi modo de ver, la importancia de ésta queda clara desde el punto de vista epigráfico. 
mos, $\mathrm{y}$ algunos investigadores piensan que sus relaciones con Cerdeña y con las costas atlánticas septentrionales, incluso más allá de la Peninsula Ibérica, pudieron haberse desarrollado con independencia de los fenicios ${ }^{+1}$. Las gentes del S.O. han podido jugar un papel puramente pasivo en el comercio tartésico, suministrando materias primas a cambio de manufacturas tartesias o fenicias, por lo que el desarrollo de una escritura local en respuesta a estímulos puramente económicos parece menos probable que en el caso tartesio ${ }^{+2}$.

En contrapartida hay ciertos aspectos originales en su respuesta al estimulo exterior que faltan en el caso tartesio. La aristocracia del S. O., tenia una tradición propia de enterramientos de prestigio, una de cuyas características más notables era el empleo de las mencionadas losas sepulcrales, que da lugar posteriormente al tipo de las llamadas estelas extremeñas, con armas grabadas en los casos más simples y con figuras humanas e incluso auténticas escenas en los tipos más complejos ${ }^{43}$. Esta tradición explica probablemente el que las gentes del S. O., con o sin el estimulo de la epigrafia sepulcral oriental, hayan desarrollado su característico grupo de inscripciones, relativamente bien atestiguado y que contrasta con la pobreza de otros indicios epigráficos, tan escasos en la zona como en el propio territorio tartesio ${ }^{44}$.

El caracter exclusivo casi de la epigrafia sepulcral, unido a la torpeza que frecuentemente se observa en las lápidas, y que tal vez incluya auténticos errores de grafia ${ }^{45}$, me hace pensar que la escritura del S. O. nació como aportación tartesia a una demanda de la aristocracia del S. O., interesada en añadir un elemento más de prestigio a su repertorio, que tenia la ventaja de unir el valor de las novedades orientalizantes a la propia tradición ritual. Pero no creo que la escritura llegase a ser una práctica corriente en aquel mundo, lo que explicaria su desaparición total o casi total a partir de digamos el siglo $\mathrm{v}$, bajo la presión de dos hechos muy distintos, la crisis de la cultura tartesia, y por lo tanto el cese de su papel fertilizador, y la penetración de grupos humanos desde la Meseta portadores de otra lengua y otra cultura, que no llegan a asimilar la escritura entre los préstamos que reciben de las poblaciones autóctonas, a pesar de algún testimonio de que sus primeros caudillos, en un momento inicial de mestizaje y cuando la influencia de los recién llegados aún no se había hecho predominante, pudieron llegar a ser enterrados al amparo de una estela del S. O. en lengua indigena pero en la que figuraba su nombre indoeuropeo; es el caso del Akosios de la estela de Almoroqui ${ }^{46}$.

Cuando pasamos del mundo tartésico al ibérico, hay una primera gran diferencia que condiciona el uso que ambas sociedades hicieron de la escritura. La cultura orientalizante tartésica era, básicamente, la cultura de un estamento social minoritario que controlaba la producción de los bienes en los que estaba interesado el comercio internacional, y aunque las influencias orientales vayan penetrando poco a poco en la forma de vida del conjunto de la población, dando

41 Almagro-Gorbea, 1986: «Bronce Final», 356, 419-420, 430-434. Cf. para Cerdeña la discusión de Gras, M., 1985: Trafics tyrrhéniens, 120-121.

42 Parreira, R., 1993: «Espaço e Tempo», 6.

43 Almagro Basch, M., 1966: Las estelas; Barceló, J. A., 1989: «Las estelas»; Celestino, S., 1990: "Las estelas».

44 Beirâo \& Gomes, 1985: «Grafitos».

45 de $\mathrm{Hoz}, 1989$ : «El desarroHo», 537.

4h Falta un estudio adecuado de esta estela sobre la que en 1980 envié un artículo a la imprenta que, por diversas causas, aún no ha aparecido (de Hoz, en prensa, "La inscripción»); puede verse provisionalmente Beltrán, M., 1973: Estudios, 94-97; Almagro-Gorbea, M., 1977: El Bronce Final, 265-266. 
lugar por ejemplo a nuevas técnicas cerámicas y constructivas, el cambio que se produce en aquélla no es comparable con el rápido desarrollo de los rasgos diferenciales de la aristocracia tartesia y de la peculiar cultura que le sirve de señas de identidad. En el mundo ibérico, por el contrario, aunque no falten las diferencias sociales, existe una cultura común mucho más generalizada de la que participan los distintos grupos y estamentos, a la vez que el área geográfica de esa cultura es mucho más extensa que la de la cultura tartesia en sentido estricto ${ }^{47}$.

Esa misma extensión sin embargo plantea un problema dificil en la interpretación histórica de la escritura ibérica. En el caso de los tartesios, sin necesidad de conocer el lugar concreto en que nació su escritura podiamos comprender el que se generalizase a partir de su origen fenicio a la totalidad del área nuclear de su cultura, aunque limitándose a un estrato social reducido. En el caso ibérico esto resulta mucho menos comprensible, como veremos, y como por otra parte la escritura utilizada por los iberos no fue una sino al menos tres, nuestra ignorancia de la zona concreta en que nació cada una de ellas, y del proceso de expansión por el que se extendió a otros territorios, constituye un impedimento grave para entender las circunstancias históricas que explican el uso ibérico de la escritura.

No lo ignoramos todo sin embargo sobre el proceso de desarrollo de la escritura en el mundo ibérico, y conviene que empecemos por recapitular lo que sabemos. La lengua ibérica se ha escrito en la escritura que denomino meridional, en la ibérica propiamente dicha, y en la greco-ibérica ${ }^{4 x}$.

La escritura meridional es una escritura andaluza que o es idéntica a la tartesia o deriva directamente de ésta, y que, como creo haber demostrado en otro lugar, no es probable que fuese creada para escribir ibérico ${ }^{40}$. Las inscripciones meridionales en lengua ibérica se encuentran en la Alta Andalucía desde Cástulo hacia oriente, en Almería, Albacete y Alicante, pero en esta última provincia parecen desaparecer a partir del siglo III, en el que sólo se encuentran inscripciones en la escritura ibérica propiamente dicha ${ }^{50}$. La utilización por los iberos de la escritura meridional, que está atestiguada desde al menos el siglo IV, pero que como veremos sin duda debe de ser anterior, es indiscutiblemente resultado de la influencia tartesia, pero no podemos precisar en qué zona de las sometidas a esa influencia se ha originado, ni si ha llegado por vía terrestre Guadalquivir arriba o por vía maritima a las costas alicantinas. El número de inscripciones ibéricas en escritura meridional es relativamente reducido, en todo caso mucho más reducido que el de las inscripciones en escritura ibérica propiamente dicha $^{51}$, y por ello, y también por los muchos problemas sin solucionar que todavía plantea

\footnotetext{
${ }^{47}$ Almagro-Gorbea, 1986: "Bronce Final», 472-510; 1990: "Segunda edad del hierro», 516-550; Iniesta, 1989: «Los iberos»; Abad, L., 1987: «La cultura ibérica».

${ }^{48}$ La bibliografía se encontrará en su mayor parte en Untermann, $M L H$, en especial $M L H$ III 1. Panoramas rápidos en de Hoz, 1983: «Las lenguas»; Untermann, 1980: «Hispania»; 1983: «Die althispanischen Sprachen").

49 de Hoz, 1993: «La lengua y la escritura ibéricas», 641-644.

so Llobregat, E., 1972: Contestania, 130-131.

s1 de Hoz, J., 1976: «La epigrafia prelatina meridional»; en prensa: «Notas»; Fletcher, D. \& Bonet, H., en prensa: «Bastida VI»; Untermann, $M L H$ III 2, F.9.2 (y quizá F.9.4A), G.0.1, G.5.1 (poco probable), G.6.1, G.7.1-2, G.12.1-3, G.14.1-2, G.15.1, G.16.1-5, G.17.1, G.18.1, y todo el grupo H excepto H.3.4 y H.6.1 en escritura latina, y H.12.1, cuyos ilegibles rastros tanto podrían ser de escritura griega como hispánica. Habría que plantearse también la posible autenticidad del plomo y el plato recogidos en $M L H$ III 1, 102-103, y considerados falsos por Untermann.
} 
aquella escritura ${ }^{52}$, sólo las utilizaremos secundariamente, como datos complementarios, en el estudio de la función de la escritura entre los iberos.

En cuanto a las inscripciones greco-ibéricas, se trata de un pequeño número de textos ${ }^{53}$, al parecer todos ellos del siglo IV, aunque creo que se puede afirmar que la adaptación del alfabeto jonio para escribir ibérico utilizaba en estas inscripciones se originó en el siglo $\mathrm{v}, \mathrm{y}$ todos procedentes de Alicante o Murcia, es decir del territorio de los iberos contestanos o de sus proximidades inmediatas ${ }^{54}$.

Por último la escritura ibérica propiamente dicha ${ }^{53}$, sobre la que se basarán en lo esencial las páginas siguientes, está sin duda genéticamente relacionada con la meridional, con la que comparte rasgos de estructura esenciales como el semisilabismo, y se deja ver en un número relativamente alto y continuamente creciente de inscripciones, de tipos variados, desde el río Herault, en Languedoc occidental, a lo largo de las costas mediterráneas hasta el Segura, con una profunda penetración por el valle del Ebro hasta al menos Zaragoza, en donde se establece la frontera con otra área epigráfica, la de los celtíberos, cuya escritura no es sino una adaptación de la ibérica sin apenas cambios ${ }^{56}$. La inscripción ibérica más antigua conocida hasta la fecha alcanza los años finales del siglo $\mathrm{v}, \mathrm{y}$ las más modernas pertenecen ya al período romano y es posible que alcancen la época imperial ${ }^{57}$.

El problema del origen de la escritura ibérica, que incide muy directamente, como veremos, sobre el tema que ahora nos ocupa, aunque claro en algunos aspectos esenciales, plantea preguntas todavia irresolubles sobre las que habremos de volver.

Como he dicho la epigrafia ibérica es abundante y variada, lo que implica ya una importante diferencia con respeto a la tartesia ${ }^{58}$. Por una parte contamos con los banales grafitos cerámicos que nos proporcionan los testimonios más antiguos, pero además, junto a tipos más significativos aunque no peculiares, como las lápidas sepulcrales, existe un documento muy característico de la cultura ibérica, la lámina de plomo con inscripción grabada, que constituye un testimonio de primera importancia para definir adecuadamente la función de la escritura en la sociedad ibérica. No cabe sin embargo prescindir de los restantes tipos de epigrafes.

Los más banales como he dicho son los grafitos cerámicos ${ }^{54}$. Se trata de un uso secundario de la escritura, cuya práctica tiene siempre por supuesto otras motivaciones, pero puede ser

52 Las lecturas utilizadas en $M L H$ III, y defendidas en III 1, 140-146, pueden ser contrastadas con de Hoz, 1989: «El desarrollo», y en prensa: «El signario hispánico».

${ }^{53} \mathrm{MLH}$ III 2, G.1.1, 3, 7 y 8 (G.1.2 creo que es probablemente falso), G.2.1, G.3.1, G.4.1, G.9.1-15, G.13.1; Muñoz, A. M., 1990: «Plomo ibérico»; Fletcher, D. \& Silgo, L., 1991: «Plomo ibérico».

s4 de Hoz, 1987: «La escritura greco-ibérica». La atribución del último plomo publicado a la zona de Sagunto debe ser puesta en duda, como tantas otras atribuciones de objetos no procedentes de excavación regular. C.1.9(a), inscripción ibérica en caracteres griegos, podria ser testimonio del uso ocasional de la escritura griega por un ibero de la zona ampuritana, o una auténtica inscripción greco-ibérica llegada del S.E.

55 Gómez-Moreno, 1943: «La escritura ibérica»; Untermann, MLH III 1.

st de Hoz, 1986: «La epigrafia celtibérica»; Untermann, 1983: «Die Keltiberer».

57 C. 2.30 es la más antigua; sobre la epigrafia ibérica de época romana vid. de Hoz, en prensa: «Escrituras en contacto».

${ }^{58}$ Sobre los usos epigráficos ibéricos en general Untermann, $M L H$ III 1, y de Hoz, en prensa: «Escrituras en contacto».

59 Maluquer de Motes, J., 1968: Epigrafia, 56-57, 59-64 y 111-127; Untermann, MLH III 1, $127-$ 128; de Hoz, en prensa: «Escrituras en contacto". 
interesante, cuando se da en abundancia, como indicio de una familiaridad considerable con aquélla, sin que sea cierto lo contrario.

Un número considerable de grafitos ibéricos es resultado de hallazgos superficiales o asistemáticos, y no puede ser valorado desde un punto de vista no ya estadistico sino ni siquiera como estimación grosera de la mayor o menor frecuencia de grafitos en un yacimiento. En algunos casos sin embargo, aunque sin llegar a grandes precisiones, podemos estimar al menos si los grafitos son raros o si abundan más de lo normal; no ocurre esto último hasta la fecha en ninguna necrópolis, pero si en lugares de habitación, sin que se vea claro un patrón de distribución territorial. Tampoco cabe contentarse como explicación con el caracter caprichoso e innecesario de la marca de propietario, porque esto justificaría pequeñas diferencias de frecuencia dentro de un uso nunca muy común, pero no ciertas concentraciones locales que exigen una interpretación. Por razones que sólo más adelante nos resultarán claras es significativo que entre los escasos puntos en que se da esa concentración haya que citar Ensérune, el punto avanzado del comercio ibérico en el sur de Francia, Ullastret, el poblado ibérico en intima relación con la colonia griega de Ampurias, y la isla de Campello, en las proximidades de Alicante, en la que conviven grafitos greco-ibéricos y púnicos, dando testimonio del caracter complejo de su población que, unido a su posición geográfica, se explica ante todo por el caracter de mercado que debió defínirla ${ }^{\text {to }}$.

En cuanto a inscripciones de propiedad sobre objetos de mayor valor o al menos no tan comunes como la cerámica, son bastante poco frecuentes ya que apenas si podemos mencionar un casco con escritura meridional ${ }^{61}$, una falcata ${ }^{\mathrm{n} 2}$, algunos objetos de hueso ${ }^{6.3}$, dos mosaicos y algunos recipientes de plata, con el agravante de que excepto en el caso del casco podria tratarse de otros tipos de inscripción, $y$ de que los epigrafes sobre vajilla de plata ${ }^{\text {th }}$ y sobre mosaico ${ }^{65}$ representan desarrollos tardios, e incluso pueden ser considerados sintomas de romanización. En contrapartida hay que subrayar que algunas inscripciones sobre armas de hierro se han podido perder sin dejar rastro, dado el estado en que a menudo aparece ese metal.

Otros tipos de inscripción que, sin llegar a ser tan banales como las de propiedad, constituyen aprovechamientos secundarios de la escritura, y sólo proporcionan indicios indirectos, a través de su mayor o menor frecuencia, sobre el grado de desarrollo de aquélla, son las firmas de artistas, las inscripciones votivas y las sepulcrales. El problema estriba en que, con la excepción de las sepulcrales que se dejan definir por sus rasgos externos, la delimitación de los otros tipos resulta todavía muy dudosa debido a nuestra casi total ignorancia de la gramática y el léxico ibéricos. Algunas de las posibles inscripciones de propiedad sobre objetos de valor podrian ser alternativamente firmas de artesanos, $y$ las inscripciones en escritura meridional sobre los platos de Abengibre ( $M L H$ G.16), que posiblemente, aunque no con absoluta seguridad, están escritas en lengua ibérica, presentan indicios de ser votivas y de proceder del tesoro de un santuario. En todo caso, y aunque luego veremos otros posibles casos de firmas de artistas, se trataria en el mejor de los supuestos de tipos poco frecuentes.

${ }^{60}$ MLB B.1, C.2, G.9; Llobregat, 1989: "Los "graffiti"»; de Hoz, en prensa: "Griegos e iberos».

${ }^{61}$ Procedente de la necrópolis de Pozo Moro, según amable comunicación de M. Almagro-Gorbea.

${ }^{62}$ de Hoz, 1992: «La inscripción».

${ }^{63}$ E.6.3, F.15.1, y Bonet, Helena \& Mata, Consuelo, 1989: «Nuevos grafitos».

${ }^{64}$ MLH C.12.1-5, H.2.1, H.3.1-2, H.5.1, H.7.1, H.9.1, H.13.1.

${ }^{65}$ E.7.1, y Vicente, J. D., M. ${ }^{a}$ A., 1991-1992: «Pavimento», y 1992: «Inscripción ibérica». 
Bastante mejor atestiguadas están las inscripciones sepulcrales, que añaden además el interés de poder ser enmarcadas en el conjunto general de las prácticas funerarias ibéricas, que a su vez han sido ya estudiadas desde diversos puntos de vista como indicador de la estructura social de los iberos ${ }^{\text {the }}$.

Las lápidas sepulcrales tienen una distribución limitada dentro del territorio ibérico; por el sur no traspasan la frontera de los edetanos, aunque existen un par de excepciones muy dudosas, y por el norte se detienen en Ampurias; por el valle del Ebro penetran tan sólo hasta Caspe $y$ el curso bajo del Cinca. La frontera meridional es particularmente significativa porque coincide con la septentrional de las típicas necrópolis ibéricas del Sudeste, caracterizadas por rasgos distintivos de ritual y ajuares, y sobre todo por las tumbas monumentales, turriformes o con pilares esculpidos en un primer momento, y de ensanchados tumulares posteriormente. Las lápidas sepulcrales faltan en esa área, que coincide básicamente con el territorio que las fuentes atribuyen a los contestanos, y faltan también en otro territorio ibérico, el de la Alta Andalucía, en donde en los territorios atribuibles a los iberos oretanos y a los bastetanos se detectan necrópolis de otro tipo, cuyos rasgos más distintivos son las cámaras sepulcrales y las cajas funerarias ${ }^{67}$. Rasgo común a ambos horizontes, el del Sudeste y el de la Alta Andalucía, es el acusado desarrollo de la jerarquización social que manifiestan los usos funerarios, y que en ambos casos culmina en lo que pudiéramos llamar tumbas principescas de una aristocracia dominante y capaz de acumular riquezas si no directamente comparables con las de la anterior aristrocracia tartesia, ya que en ellas falta la abundancia de metales valiosos que encontrábamos en las tumbas de ésta, tal vez superiores en algunos casos en valor relativo a juzgar por la calidad del trabajo escultórico o arquitectónico que conllevan. Por ello es significativo que, al igual que ocurría en el caso de los tartesios, y a diferencia de lo que observamos en otras sociedades mediterráneas como la etrusca, la aristocracia ibérica de la Alta Andalucía y del Sudeste no haya sentido interés por incorporar la escritura a los símbolos de status de sus tumbas.

No ocurre lo mismo entre edetanos, ilercavones, ilergetes y algunos de los pueblos menores de Cataluña, entre los que encontramos las lápidas sepulcrales inscritas, en casos, en especial el de Sagunto, con notable abundancia. Claro está que por el momento carecemos de criterios de datación puramente ibéricos, por lo que sólo podemos fechar aquellas lápidas que muestran claros indicios de influencia romana, y éstas son mayoria en lugares como Ampurias o Tarraco, y no faltan en Sagunto, por lo que cabe la posibilidad de que en algunas zonas, sobre todo en Cataluña, el desarrollo de la lápida sepulcral inscrita sea consecuencia de los comienzos del proceso de romanización ${ }^{68}$.

En todo caso la peculiar distribución de este tipo de epígrafes, unida a las variantes geográficas de las necrópolis que en relación con ellos hemos debido citar, nos pone frente a un problema general de la epigrafia ibérica ya mencionado pero sobre el que será necesario insistir reiteradamente; no existe en realidad una única epigrafia ibérica sino varias. A diferencia

${ }^{60}$ Congreso de arqueologia ibérica, 1992, y en especial «Las necrópolis ibéricas» de AlmagroGorbea con la bibliografia anterior alli citada.

${ }_{67}$ Vid. mapa 2 en de Hoz, en prensa: «Paleohispanic Societies»; aunque en él se combinan datos que pertenecen a momentos cronológicos distintos, son sin embargo significativas las distintas tradiciones funerarias.

${ }^{68}$ Beltrán, F., 1993: «La epigrafia», 250-252; de Hoz, en prensa: «Escrituras en contacto». 
de lo que veiamos en el caso tartesio o en el del S.O.. y de forma comparable, aunque en un grado menor, al caso griego prehelenístico, la cultura ibérica se nos presenta, desde el punto de vista epigráfico y desde el de otros criterios culturales, como un mundo diversificado geográficamente, entre cuyas distintas regiones las diferencias pueden llegar a ser considerables. La homogeneidad lingüística de las inscripciones ibéricas, indiscutible, no debe hacernos cerrar los ojos a las diferencias epigráficas locales bien visibles, y a otras, menos evidentes, que puedan surgir como consecuencia de nuevos hallazgos o de análisis más finos.

Hasta aqui nos hemos ocupado de inscripciones que han sido como si dijéramos añadidas a un objeto que tenia ya su propia personalidad como útil funcional o simbólico con anterioridad a la aparición de la escritura ibérica. En lo que sigue nos ocuparemos de dos categorias de inscripciones en las que la escritura posee o una total autonomia, y existe sólo en cuanto escritura, o una mayor independencia aun siendo solidaria de otro artefacto cultural; podemos hablar de textos autónomos y de inscripciones semi-independientes.

En este segundo caso se sitúan aquellas inscripciones que están grabadas sobre objetos que podrian existir sin ellas, pero en los que el texto escrito ha llegado a alcanzar tal importancia que prácticamente ha llegado a redefinir el objeto, y le ha proporcionado una personalidad plenamente diferenciada de la de sus congéneres no inscritos. Naturalmente no existe una línea divisoria neta entre este caso y el de las inscripciones meramente añadidas, y la diferenciación de ambas categorias es en buena medida cuestión de conveniencia; de hecho podrian aducirse buenos motivos para incluir las lápidas sepulcrales en el grupo de las inscripciones semi-independientes, pero dada la tradición de losas decoradas que precede a, y convive con, las inscripciones sepulcrales en algunas zonas del territorio ibérico he obtado por incluirlas en el grupo de inscripciones añadidas.

El interés de las inscripciones semi-independientes estriba en que a mi modo de ver implican una cierta familiaridad con la escritura, un estadio en el desarrollo de ésta en el que una parte no desdeñable de la población está acostumbrada a la presencia de textos escritos aun en el supuesto de que no esté en condiciones de leerlos. Al menos esto es lo que creo se puede deducir del tipo ibérico que mejor representa esta categoría, las inscripciones integradas en la decoración de vasos cerámicos, tal como la vemos en Liria ${ }^{\circ 9}$.

La cerámica de Liria se caracteriza en efecto, junto con su decoración pintada, por la frecuencia con la que en ella aparecen inscripciones también pintadas de dos tipos; el más común son los letreros que, según la clase de recipiente, adornan los labios o la parte superior del vaso, y en los que a menudo se repiten ciertos elementos léxicos y gramaticales; con menor frecuencia se encuentran también textos integrados en la decoración pintada, y que parecen guardar una relación con las escenas representadas. Este último tipo tiene buenos paralelos en algunos periodos de la historia de la cerámica griega, e incluso alguno en la Roma republicana, mientras que el primero es difícil de valorar mientras no tengamos algo más de información lingüística; no es improbable que en algunos casos se trate de inscripciones dedicatorias, o de firmas de artista, pero en todo caso están integradas, como las del tipo anterior, en la decoración de la cerámica, y contribuyen a la definición de su estilo. Se trata por lo tanto de un género en el que - aunque puedan existir piezas sin inscripción - la escritura no es mero

${ }^{69}$ MLH F.13.3-70; de Hoz, 1992: "La inscripción», 324; Bonet, Helena, Mata, Consuelo \& Guérin, P., 1990: «Cabezas votivas», 190-191. 
añadido, sino que se ha creado un tipo cerámico nuevo integrado en él la escritura. Lo mismo cabe decir del estilo emparentado de las cerámicas de Alloza, en Teruel (MLH E.4.1-4).

Por último tenemos que ocuparnos de la categoría de textos más significativa para valorar la función de la escritura en una sociedad, y a la vez la que, salvo excepciones como el caso mesopotámico o ciertos aspectos de la epigrafia griega, suele dejar menos huellas en el registro arqueológico, los textos autónomos.

No tenemos ninguna noticia sobre la utilización por los iberos de materiales perecederos como los conocidos por las culturas que más directamente les han influido desde el punto de vista escriturario; tampoco tenemos indicios de que entre ellos haya existido una epigrafia pública, ligada a instituciones oficiales ${ }^{70}$, a pesar del evidente desarrollo de la ciudad en algunas zonas. Tan sólo cabria mencionar, en fecha ya avanzada, las leyendas monetales ${ }^{71}$, que por muy interesantes que puedan ser como indicio de las posibilidades de desarrollo de una epigrafía pública, en sí mismas son claramente inscripciones añadidas al objeto monetal, que es el realmente significativo. Otros posibles indicios, en concreto algunas inscripciones más o menos monumentales en piedra, resultan todavía totalmente enigmáticas, no se puede asegurar en absoluto que tengan caracter público, y en todo caso serian demasiado escasas como para tener excesivo significado.

Los textos autónomos ibéricos se limitan por lo tanto al parecer esencialmente a la esfera privada. En primer lugar hay que mencionar algún ejemplo de óstraca (C.3.1), es decir fragmentos de cerámica reutilizados como material barato de escritura, de acuerdo con un uso ocasional bien conocido en el mundo griego, pero en el que precisamente por su caracter ocasional no merece la pena detenerse. El soporte de escritura realmente característico del mundo ibérico, y el que nos permite sacar mayores conclusiones sobre la función de aquélla entre los íberos es sin duda la lámina de plomo ${ }^{72}$.

Conocemos en efecto un número alto y creciente de laminillas de plomo procedentes de casi todo el territorio ibérico, en las que están representadas las tres variedades de escritura aunque predomina ampliamente la ibérica propiamente dicha, cuyas fechas varian desde el siglo IV hasta época posiblemente romana, y que proceden sobre todo de lugares de habitación aunque unos pocos ejemplares han aparecido en tumbas. Se trata de láminas escritas por una o ambas caras, de dimensiones variables aunque siempre reducidas, a veces no determinables con seguridad no sólo por los desperfectos sufridos sino porque algunas muestran huellas claras de reutilización, lo que a veces ha implicado recortes; su grosor sin embargo sí suele mantenerse en límites similares, y desde luego han sido preparadas con el objeto único de servir de soporte a un texto.

El uso del plomo como soporte de escritura no es exclusivo de los íberos; los primeros testimonios remontan el mundo neohitita en el que existen un par de documentos privados en ese material, pero sobre todo, y sin contar algunas referencias literarias, tenemos un número creciente de textos griegos, aparte del caso especial y bien conocido en la epigrafia griega y latina de las defixiones o tablillas de imprecación que se solian depositar en las tumbas. Los plomos griegos están atestiguados desde época arcaica hasta época helenística avanzada, y

70 Posibles testimonios en de Hoz, en prensa: «Escrituras en contacto».

7 Untermann, $M L H \mathrm{I}$.

72 de Hoz, 1979: «Escritura e influencia»; 1987: «La escritura greco-ibérica»; en prensa: «Griegos e íberos»; Untermann, 1987: «La gramática». 
aunque existen ejemplos atenienses y de otras zonas de la Grecia central, proceden sobre todo de zonas marginales, del Mar Negro, de la región de Marsella y de Ampurias, y en los últimos años sobre todo de Sicilia, donde los descubrimientos se multiplican ${ }^{73}$. Los testimonios masaliotas y ampuritanos, y algún ejemplo galo en escritura galo-griega, que sin duda depende de la influencia griega en el Sur de Francia, unido a que algunos de los más antiguos testimonios de plomos ibéricos están en escritura greco-ibérica, nos llevan a la conclusión de que fueron los griegos quienes transmitieron a los iberos esta técnica epigráfica.

Es significativo el tipo de textos que encontramos en los plomos griegos; se trata de cartas privadas, relativas a cuestiones mercantiles, y de contratos de compra, reconocimientos de deuda o documentos similares. En general en ellos nos movemos en el mundo de las actividades económicas, y más concretamente en el mundo de la economía privada de los mercaderes o de los propietarios de tierras y casas. Naturalmente nuestra ignorancia de la lengua ibérica no nos permite llegar a conclusiones tan precisas sobre los plomos ibéricos, pero aparte la presunción que aporta el caracter de sus modelos griegos, contamos con ciertos indicios sobre los que basar nuestras conclusiones. Podemos reconocer los nombres de persona ibéricos, y en algunos plomos podemos advertir que se trata de listas de personas en las que a cada nombre sigue una indicación numeral, es decir posiblemente listas de deudores o acreedores; en general es frecuente la aparición de cifras con referencia a un par de sistemas metrológicos distintos, lo que parece confirmar al caracter económico de muchos de estos textos. Por último algunos parecen reproducir la estructura externa de las cartas griegas sobre plomo, con el texto principal en una de las caras y en la otra un texto menor, normalmente la indicación del destinatario.

Podemos concluir por lo tanto que los plomos ibéricos nos sitúan, salvando las inevitables diferencias entre ambas sociedades, en el mismo ambiente que los plomos griegos, el de los mercaderes y propietarios y sus actividades económicas. Lo más significativo es que sea precisamente esta clase de textos la mejor atestiguada en el mundo ibérico, tanto en número de epígrafes como en distribución cronológica y geográfica, lo que les confiere una posición decisiva a la hora de valorar la función de la escritura entre los íberos.

Pero antes de abordar esa cuestión esencial conviene aclarar ciertas cuestiones previas, de gran significación histórica, que condicionan cualquier conclusión a la que pueda llegarse sobre la escritura entre los íberos.

La lengua ibérica tal como precariamente podemos definirla por el momento, es decir una lengua caracterizada por una estructura fonética que conocemos relativamente bien, por un pequeño grupo de morfemas que hemos aislado y de cuya distribución sabemos algo pero prácticamente nada de su función, por un sistema onomástico bastante claro, y por algunos lexemas característicos de cuyo valor semántico no sabemos prácticamente nada ${ }^{74}$, está atestiguada en un área muy amplia que comprende todo el territorio en que se encuentra la escritura ibérica propiamente dicha, y que ya he delimitado más arriba, y además la zona del S.E., de la Peninsula en que se utiliza la escritura meridional hasta la antigua Obulco, la actual Porcuna, en cuyas inscripciones monetales, de época ya romana, tenemos testimonios de contacto de lenguas que indican una zona fronteriza ${ }^{75}$. Originalmente Obulco parece estar enclavada en

${ }^{73}$ Bibliografia en de $\mathrm{Hoz}$, en prensa: "Griegos e iberos», n. 7, 8, 22 y 39, y entre los escasos planteamientos generales Bravo, B., 1974: «Une lettre».

74 Michelena, L., 1979: "La langue ibère»; Untermann, $M L H$ III I, 150-238.

7 Untermann, $M L H$ I, A.100; 1985: "Lenguas y unidades», 14. 
territorio no lingüisticamente ibérico, mientras que en Cástulo tenemos indicios de iberismo desde al menos los comienzos del siglo IV, por lo que parece que la frontera lingüistica pasaria entre Cástulo y $\mathrm{Obulco}^{7 \mathrm{~T}}$.

La cuestión se complica sin embargo ya que, según he defendido en otro lugar, creo que no hay motivos para pensar que el área en que está atestiguada la lengua ibérica coincida con el área en que ésta se hablaba como lengua coloquial y nativa "; más bien creo que estamos en presencia de un tipico caso de lengua vehicular, utilizada para la relación entre comunidades diversas, que ha ejercido una influencia muy amplia como única lengua escrita de una gran parte de la Hispania antigua, y que incluso ha podido prestar a otras lenguas no sólo elementos léxicos sino su propia antroponimia como sistema onomástico de prestigio. Naturalmente esta teoria plantea inevitablemente la cuestión de cuáles fueron las zonas en las que realmente se hablaba ibérico como lengua nativa.

La escritura grego-ibérica, que en el estado actual de la documentación parece ser especifica de los contestanos, nos proporciona una primera aproximación al problema, ya que se trata de una adaptación del alfabeto griego para escribir ibérico realizada en las costas alicantinas ${ }^{78}$, y por tanto en esa zona el ibérico era la lengua habitual. Por desgracia no sabemos en qué lugar se creó la escritura ibérica propiamente dicha ni en qué punto se empezó a usar la escritura meridional para escribir ibérico, pero ya he indicado que en Cástulo la lengua ibérica está atestiguada en fecha temprana, y seguirá utilizándose, siempre con la escritura meridional como medio escrito, en época ya romana, pero si en esa zona el uso del ibérico correspondiese sólo al de una lengua vehicular y especializada, llegada de fuera, lo lógico sería que también alli hubiese acabado generalizándose la escritura ibérica propiamente dicha.

Creo por lo tanto que en la Alta Andalucía el uso del ibérico no es resultado de ninguna influencia externa, sino que responde a la realidad lingüistica de la zona, y que alli mismo, en directo contacto con la cultura tartesia por la vía del Guadalquivir, y bajo fuerte influencia de ésta desde fechas muy tempranas, pudo tomarse en préstamo la escritura meridional tartesia para transcribir ibérico, fuese éste el mismo que el de la zona contestana o una variedad dialectal más o menos divergente.

Pero una vez admitido esto se nos hace evidente un rasgo del uso de la escritura en la zona en el que hasta ahora no hemos reparado, su total coincidencia con el área tartesia en lo que se refiere a la documentación epigráfica. En ambas zonas encontramos la misma escasez de epigrafes y los mismos tipos, y puesto que ambas zonas, aunque con un desfase cronológico, son zonas de producción de mineral, y controladas por una aristocracia restringida a la que cortejan los mercaderes extranjeros, creo que podemos extrapolar las conclusiones a las que hemos llegado sobre el uso de la escritura entre los tartesios y extenderlas al uso de los íberos de la Alta Andalucia.

En Contestania la situación es sin embargo diferente. Como ya hemos visto allí no sólo se ha utilizado la escritura meridional sino también la ibérica propiamente dicha, que ha acabado imponiéndose, $y$ además en el siglo $v$ se ha inventado la escritura greco-ibérica. Por otro lado es un territorio en el que también tenemos atestiguada una aristocracia con caracteristicas hasta cierto punto similares a las de la Alta Andalucía, pero cuyo acumulación de bienes de

\footnotetext{
${ }^{76}$ de Hoz, 1993: «El desarrollo», 563.

77 de Hoz, 1993: "La lengua y la escritura».

78 Vid. supra.
} 
prestigio no pudo deberse al control de productos naturales sino más bien al de las vías que comunicaban la costa con la Alta Andalucia ".

La escritura meridional ha llegado sin duda del oeste, probablemente a través de los iberos de la Alta Andalucia a los que ya hemos visto utilizarla, aunque no es del todo imposible que los prestatarios hayan sido directamente los tartesios por via maritima tal como sugiere un grafito muy arcaico de la Peña Negra de Crevillente ${ }^{\mathrm{x} 1}$, uno de los poblados en que se manifiestan los primeros testimonios de aculturación fenicia y tartesia de la zona, pero muy pronto, ya en el siglo $\mathrm{v}$, la influencia griega es lo suficientemente intensa como para que, junto a la escritura meridional, los contestemos desarrollen otro sistema, el greco-ibérico, y no sólo eso, también en el siglo $\mathrm{V}$ - como demuestran los primeros testimonios epigráficos-iberos que pueden haber sido los mismos contestanos, y que en todo caso se hallaban dentro de la misma área cultural sometida a influencias tartesias, pero en su borde oriental, transforman la escritura meridional en la ibérica propiamente dicha por motivos que por ahora no podemos precisar en detalle, pero en los que sin duda jugó un papel el deseo de aproximar más la escritura a las peculiaridades fonéticas de la lengua, y tal vez también la influencia griega ${ }^{* 1}$. Todas estas innovaciones implican una sociedad mucho más preocupada por la escritura que lo que nuestra documentación parece implicar para el área tartesia o la de la Alta Andalucia, y a ello se une el panorama epigráfico de Contestania, mucho más rico y variado.

No parece que la aristrocracia contestana, si no se diferenciaba netamente de la tartesia y de la de la Alta Andalucia en su talante y en su actividad económica, haya podido ser la responsable de toda esa efervescencia epigráfica; tenemos que contar con factores nuevos, y buscar indicios para su definición en el registro documental.

Quizá el rasgo más llamativo esté, junto en la proliferación de plomos inscritos, en la evidente predisposición a las relaciones con otros pueblos y regiones que demuestran ciertos iberos, algunos de ellos con seguridad del S.E., a partir del siglo v. Ya la escritura meridional, aunque haya acabado por ser abandonada, participa en el S.E., de estas tendencias; tenemos plomos en esa escritura, algunos de caracter claramente económico, y por lo menos un par de ellos han viajado fuera de los límites esperables, hasta Castellón e incluso el Sur de Francia ${ }^{\mathrm{x} 2}$. La escritura greco-ibérica por su parte expresa claramente esa predisposición al intercambio, y subraya la importancia de la presencia griega en la zona S.E., y como vimos, en el mismo sentido podemos interpretar la difusión del uso de las tablillas de plomo como soporte de escritura.

Precisamente son testimonios griegos los que nos permiten avanzar más en esta investigación. Un contrato griego de Pech-Maho nos muestra como en el siglo $\mathrm{V}$ una importante transacción comercial en el Sur de Francia podia implicar a gentes de tres grupos étnicos distintos, los colonos focenses, un impreciso elemento en el que creo que debemos ver a los indígenas de

79 Vid. en último lugar, con referencias a la bibliografia anterior - a las que habria que añadir Trias, G., 1967-1968: Cerámicas I, XXXVIII-XLII-, Rouillard, P., 1991: Les Grecs, 323-324 y 326330 ; en éstas últimas páginas se subraya el comportamiento paralelo, en lo que a signos externos se refiere, de las sociedades del S.E., y la Alta Andalucia, pero no los muy diferentes recursos locales.

${ }^{* 0}$ de Hoz en González Prats, A., 1982: La peña Negra IV, 385; González Prats, 1983: Estudio arqueológico, 231, 275 y lám. 5 de p. 297.

${ }^{81}$ de Hoz, en prensa: «De la escritura meridional».

*2 $M L H$ F.9.2 y G. 18.1 = B.2.3. 
la zona, y los iberos ${ }^{x 3}$. Tal como yo veo los datos, los iberos eran en origen tan ajenos al Sur de Francia como los propios griegos, y su presencia alli, que no parece justificarse en absoluto por una invasión ni tan siquiera por colonizaciones de auténtica entidad, responde fundamentalmente al comercio, aunque ese comercio traiga consigo el establecimiento de pequeños grupos de inmigrantes. Pero un comercio que se incrusta entre el área masaliota estricta y el área ampuritana ${ }^{\times-1}$ parece dificilmente explicable sin una cierta colaboración con el mundo griego. En ese mismo sentido nos habla una carta griega de Ampurias en la que se menciona una transacción comercial en la que aparece implicado un individuo de nombre muy probablemente ibérico ${ }^{\mathrm{x}}, \mathrm{y}$ tal vez también esté relacionado el hecho de que la más antigua inscripción en escritura ibérica levantina proceda de Ullastret (C.2.30), el poblado indigena intimamente relacionado con Ampurias.

En el siglo v parece en efecto que se está consolidando una amplia área comercial en la que griegos e iberos no sólo conviven sino que parecen colaborar, y en la que por el momento es dificil precisar qué papel jugaban los fenicios occidentales y los púnicos. Ese área comercial va a consolidarse y perdurar; en ella se van a mover las cerámicas grises catalanas o las imitaciones de cerámica ática de barniz negro producidas en Rhode, y en ella van a seguir activos los iberos, y su lengua y su escritura van a jugar un papel esencial en la comunicación, como lo demuestra el reciente hallazgo en Ampurias de una carta ibérica en plomo, de hacia la transición del siglo III al II, dirigida a o por un galo, en la que la lengua ibérica se nos aparece como vehículo de comunicación en una ciudad griega y para un celta del Sur de Francia ${ }^{\mathrm{xt}}$.

Creo que en lo íberos implicados en ese ambiente comercial debemos ver a los responsables de las innovaciones epigráficas ibéricas y de la versatilidad de usos de la escritura ibérica que hemos tenido ocasión de comprobar, e imaginarlos como una comunidad activa, que ha experimentado con la escritura porque la escritura estaba intimamente ligada con su actividad mercantil, sin por eso construir la imagen rigida de un estamento geométricamente definido. En otro lugar he contrastado a los mercaderes con el elemento militar de la sociedad ibérica, a propósito de la escasez de testimonios epigráficos en relación con el conocido fenómeno del mercenario ${ }^{\times 7}$, pero no quisiera con esto fomentar artificiales dicotomías a lo Dumezil. No es que un mercader ibérico no conociese el uso de las armas, ni pudiese ser enterrado con ellas, sino que el modo de vida predominantemente militar de quienes se empleaban como mercenarios, o de las aristocracias guerreras locales, hacía poco frecuentes las ocasiones de aprender a escribir, y normal el enterramiento con armas, mientras que las actividades predominantes de los mercaderes hacían normal la alfabetización y no necesario el enterramiento con armas. Pero la sociedad ibérica nos resulta todavía excesivamente desconocida como para pretender precisiones gratuitas; tan sólo podemos vislumbrar algunas tendencias, algunos fenómenos de una cierta generalidad, y entre ellos me atrevería a considerar probable la reconstrucción de un estamento dentro de esa sociedad, en particular en su versión del S.E., que se especializa en una actividad comercial de caracter internacional, y a través de sus contactos e incluso del

${ }^{* 3}$ Lejeune, M., J. Pouilloux \& Y. Solier: 1988 (= 1990): «Étrusque et ionien», y Lejeune, M., 1991: "Ambiguïtés», donde se menciona la bibliografía restante; de Hoz, en prensa: "Griegos e iberos».

*4 Sanmarti-Grego, 1992: "Massalita et Emporion».

*s Sanmarti-Grego, E. \& Santiago, R. A., 1988 (= 1990): «La lettre grecque».

*o Sanmarti-Grego, E., $1988(=1990)$ : «Una carta en lengua ibérica».

*7 de $\mathrm{Hoz}$, en prensa: "Griegos e iberos». 
asentamiento en territorios originalmente no ibéricos facilita el desarrollo de esa cultura, común a pesar de sus variaciones locales, que llamamos ibérica, y extiende junto con ella una lengua y una escritura como vehículos de comunicación supralocal.

Hasta qué punto llegó el proceso de asimilación es imposible precisarlo por ahora; en el Sur de Francia se advierte todavía en época imperial la pervivencia de los elementos preibéri$\cos$, junto con los galos llegados a la zona en fecha relativamente tardia ${ }^{\mathrm{xx}}$, mientras que los iberos han desaparecido, tal vez porque como grupo más helenizado se latinizaron totalmente en poco tiempo. En Hispania hay que contar tambièn con esa latinización temprana ${ }^{k 9}$, pero es preciso rastrear todavia hasta qué punto se conservan restos de comunidades no ibéricas en el área de cultura ibérica.

En todo caso debemos buscar una imagen menos monolítica del mundo que llamamos ibérico. Uno de los rasgos que más han contribuido en el pasado a esa imagen monolítica han sido precisamente la lengua y la escritura, y espero haber mostrado al menos que éstas no son incompatibles con una pluralidad de pueblos y de lenguas, y que lo único que garantizan es la unidad y cohesión de un grupo social.

\section{BIBLIOGRAFÍA}

ABAD, L., 1987: "La cultura ibérica», Historia general de España y América I-2, Madrid, 171 ss.

_ : 1993: «Las culturas ibéricas del área suroriental de la Peninsula». M. Almagro ed., Paleoetnologia, $151-166$.

Actas del I coloquio sobre lenguas y culturas prerromanas de la Peninsula Ihérica (Salamanca, 1974), 1976: Salamanca.

Actas del II Coloquio sobre lenguas y culturas prerromanas de la Peninsula lbérica (Tübingen, 1976), 1979: Salamanca.

Actas del III Coloquio sobre lenguas y culturas paleohispánicas (Lisboa, 1980), 1985: Salamanca. Actas del IV Coloquio sohre lenguas y culturas paleohispánicas (Vitoria. 1985), 1987: Vitoria/Gasteiz = Studia Paleohispánica, Veleia 2-3.

Actas del $V$ Coloquio sobre lenguas y culturas prerromanas de la Peninsula Ihérica (Colonia 1989) Lengua y cultura en la Hispania prerromana, 1993: Salamanca.

Almagro Basch, M., 1966: Las estelas decoradas del Suroeste peninsular, Madrid.

Al.magro-GorbeA, M., 1977: El Bronce Final y el Periodo Orientalizante en Extremadura, Madrid (Capítulo VIII, «La Epigrafia», 263-277).

- : 1986: «Bronce Final y Edad del Hierro», F. Jordá et alii, Historia de España I. Prehistoria, Madrid, 341-352.

-- : 1987: «El pilar-estela de las "damitas de Mogente" (Corral del Saus, Mogente, Valencia)», APL 17. 199-228.

- : 1989: «Arqueologia e Historia Antigua: El proceso protoorientalizante y el inicio de los contactos de Tartessos con el Levante mediterráneo", Anejos de Gerión 2, 277-288.

- : 1990: "Segunda edad del hierro», Dominguez Ortiz, A. ed., Historia de España 1, 511-583.

— : 1990: «El periodo orientalizante en Extremadura», La cultura tartésica y Extremadura, 85-125.

- : 1991: «El mundo orientalizante en la Península Ibérica», Atti II Studi Fenici II, 573-599.

- : 1992: «Las necrópolis ibéricas en su contexto mediterráneo», Congreso de arqueología ibérica: las necrópolis, 37-75.

\footnotetext{
${ }^{8 *}$ Untermann, J., 1969: «Lengua ibérica y lengua gala».

"89 de Hoz, en prensa: «Escrituras en contacto».
} 
: 1993: "Palacio y organización social en la Peninsula Ibérica», Actas l' Coloquio, 21-48.

Almagro-Gorb1: a, M., ed., 1993: Paleoemologia de la Peninsula Iherica. Madrid.

AU131. Т, М. F.. 1977-1978: "Algunas cuestiones en torno al periodo orientalizante tartésicom, Prrenae 13-14. 81-107 (- «ur Problematik des orientalisierenden Horizontes auf der Iberischen Halbinsel», págs. 309-335 de 11. G. Niemeyer Hrsg., Phönizier im Westen, Mainz. 1982).

: 1984: "La aristocracia tartésica durante el periodo orientalizante", Opus 3, 445-468.

Atвi:T, M. E... ed.. 1989: Tartessos, Barcelona.

BarC 1:LO. J. A., 1989: "Las estelas decoradas del sudoeste de la Peninsula Ibérica». M. E. Aubet ed., Turtessos, 189-208.

Baumann, G., ed., 1986: The Written Word. Literacy in Transition, Oxford.

BE:Iráo, C: M. de Mello. 1986: Une civilisation protohistorique du Sud du Portugal (I." Age du Fer). Paris.

BeIRÁo, C. M. de Mello \& M. Varela Gomes, 1985: «Grafitos da Idade do Ferro do Centro e Sul de Portugal", Actas III lenguas y culturas, 465-499.

BELLFN, M. ${ }^{a}$ \& Escacena, J. L., 1992: «Las necrópolis ibéricas de Andalucia Occidental», Congreso de arqueologia ibérica: las necrópolis, 509-529.

BELLTRAN, F., 1993: "La epigrafia como indice de aculturación en el valle medio del Ebro (s. II a. e.-II d. e.)", Actas del V Coloquio, 235-272.

BELTRAN, M., 1973: Estudios de arqueologia cacereña, Zaragoza.

BENDALA, M., 1989: «La génesis de la estructura urbana en la España antigua», CuPAUAM 16, 127-147.

- : 1990: "Tartessos hoy a la luz de los datos arqueológicos y literarios», La cultura tartésica y Extremadura, 11-27.

-: 1992: «La problemática de las necrópolis tartésicas», Congreso de arqueologia ibérica: las necrópolis, 27-36.

BERROCAL., L., 1985: «Una nueva aportación al estudio de las estelas y escritura prerromana del Suroeste Peninsular", Boletin-Asociación española de amigos de la arqueologia, 21, 30-33.

-: 1987: «La losa de Capote (Higuera la Real, Badajoz)», AEA 60, 195-205.

BLANCO, A. \& CORZO, R., 1983 julio: «Monte Algaida. Un santuario púnico en la desembocadura del Guadalquivir», Historia 16 87, 123-128.

Bonet, Helena \& MATA, Consuelo, 1989: «Nuevos grafitos e inscripciones ibéricos valencianos», APL 29, 131-148.

Bonet, Helena, Mata, Consuelo \& Gutirin, P., 1990: "Cabezas votivas y lugares de culto edetanos", Verdolay 2, 185-199.

Bravo, B., 1974: «Une lettre sur plomb de Berezan», Dialogues d'histoire ancienne 1, 111-187.

CFlLestino, S., 1990: «Las estelas decoradas del S. W. peninsular», La cultura tartésica y Extremadura, 45-62.

CHILDE, G., 1982 (= 1942): What Happened in History, Harmondsworth.

Civiltà degli etruschi, 1985: a cura de M. Cristofani, Milano.

Congreso de arqueología ibérica: las necrópolis, 1992: Coordinadores J. Blánquez \& V. Antona, Madrid.

CORREA, J. A., 1978: «Inscripción tartesia hallada en Villamanrique de la Condesa (Sevilla)», Habis 9, 207-211.

- : 1982: «Singularidad del letrero indigena de las monedas de Salacia (A 103)», Numisma 32, 69-74.

—: 1985: La inscripción en escritura tartesia de Alcalá del Rio, Alcalá del Río.

-: 1985: «Consideraciones sobre las inscripciones tartesias», Actas III lenguas y culturas, 377-395.

- : 1987: «El signario tartesio», Actas IV lenguas y culturas, 275-284.

-: 1989: «El origen de la escritura paleohispánica». J. González ed., Estudios sobre Urso, Sevilla, 281-302.

- : 1992: "La epigrafia tartesia», Andalusien zwischen Vorgeschichte und Mittelalter, herausg. v. D. Hertel \& J. Untermann, Köln, 75-114.

-: 1993: «El signario de Espanca (Castro Verde) y la escritura tartesia», Actas del V Coloquio, 521-562.

- : en prensa: «El signario hallado en Espanca (Castro Verde)», Coloquio de Castro Verde. 
Coul.mas, F., 1989: The Writing Sistems of the World, Oxford.

C'RISTOFANI, M., 1972: "Sull'origine e la diffusione dell'alfabeto etrusco», $A N R W 1$ 2, Berlin, 466-489.

La cultura tartésica y Extremadura, 1990: Museo Nacional de Arte Romano, Mérida.

Dominciulzz ORTiz, A. ed.. 1990: Historia de España 1, Barcelona.

ENRiQUiz, J. J., 1990: «El Bronce final extremeño y su relación con la cultura tartésica», La cultura tartésica y Extremadura, 63-84.

Estudios de arqueologia ihérica y romana. Homenaje a Enrique Pla Ballester, 1992: Valencia.

EscacinA, J. L., 1989: "Los turdetanos o la recuperación de la identidad perdida», M. E. Aubet ed., Tartessos, 433-476.

FI:RNANDiz JURADO, J., 1984: La presencia griega arcuica en Huelva, Huelva.

FERNANDEZ JURADO, J. \& OLMOS, R., 1985: “Una inscripción jonia arcaica en Huelva», Lucentum 4, 107-113.

Fi:rnández Jurado, J. \& Correa, J. A., 1988-1989: «Nuevos grafitos hallados en Huelva», Huelva arqueológica 10-11, 3, 121-142.

Fletcher, D. \& Bonet, H., en prensa: «Bastida VI. Nuevo plomo escrito de la Bastida de les Alcuses (Mogente, Valencia)"), Homenaje a D. Jerónimo Molina, Murcia.

Fletcher, D. \& Silgo, L., 1991: «Plomo ibérico, en escritura jonia, procedente de Sagunto», Oxford. GómEZ-MORENO, M., 1943: "La escritura ibérica», BRAH 112, 251-278 (= Misceláneas, 257-281).

-: 1949: Misceláneas. Historia, Arte, Arqueologia. Primera serie: la antigüedad., Madrid.

—: 1962: Escritura bástulo-turdetana (primitiva hispánica), Madrid (BT).

- : González Prats, A., 1982: La Peña Negra IV, NAH 13, Madrid.

- : 1983: Estudio arqueológico del poblamiento antiguo de la Sierra de Crevillente (Alicante). Alicante.

GoOdy, J., 1986: La logique de l'ecriture, Paris.

GRAS, M., 1985: Trafics tyrrhéniens archaïques, Roma.

HARRIS, W. V., 1989: Ancient Literacy, Cambridge, Mass.

HEUBECK, A., 1979: Schrift, Archaeologia Homerica X, Göttingen.

DE HOZ, J., 1976: «La epigrafia prelatina meridional en hispania», Actas I lenguas y culturas, 227-317.

_- 1979: Escritura e influencia clásica en los pueblos prerromanos de la Península», AEA 52, 227-50.

— : 1983: "Las lenguas y la epigrafía prerromanas de la Peninsula ibérica», Unidad y pluralidad en el mundo antiguo. Actas del VI congreso español de estudios clásicos, I, 351-396. Madrid.

- : 1983: «Algunas consideraciones sobre los origenes del alfabeto griego», J. A. Fernández Delgado ed., Estudios metodológicos sobre la lengua griega, Cáceres.

- : 1985: «El origen de la escritura del S.O», Actas del III Coloquio, 423-464.

- : 1986: «La epigrafia celtibérica», Reunión sobre epigrafia, 43-102.

— : 1987: «La escritura greco-ibérica», Actas $I V$, 285-298.

—: 1989: «El desarrollo de la escritura y las lenguas de la zona meridional», en M. E. Aubet ed., Tartessos, 523-587.

- : 1990: «El origen oriental de las antiguas escrituras hispanas y el desarrollo de la escritura del Algarve», Presenças Orientalizantes em Portugal, Lisboa, 219-246.

- : 1991: "The Phoenician origin of the early Hispanic scripts", Phoinikeia Grammata, 669-82.

-: 1992: «La inscripción de la falcata», Estudios... E. Pla, 330-338.

- : 1993: "La lengua y la escritura ibéricas, y las lenguas de los iberos», Actas del V Coloquio, 635-666.

— : 1993: «De la escritura meridional a la escritura ibérica levantina», Festschrift J. Untermann, 175-190.

- : en prensa: «El signario hispánico meridional», en Homenaje a J. Maluquer.

- : en prensa: «Paleohispanic Societies and Writing», II Coloquio internacional Arqueologia Hoje, Faro.

- : en prensa: «Griegos e íberos. Testimonios epigráficos de una cooperación mercantil», Griegos e iberos, Siglos VI-IV a. C.

- : en prensa: "La inscripción en escritura del S.O., de la estela de Almoroqui».

— : en prensa: «Notas sobre inscripciones meridionales de la Alta Andalucia», Homenaje al Profesor Blázquez. 
: en prensa: "Liscrituras en contacto: ibérica y latina", Roma y las primeras culturas

INII:STA, A.. 1989: "Los iberos y la cultura ibérica". A. Montenegro et alii, Historia de España 2, 275317.

JА(')BI. (i., 1974: «Zum Schriftgebrauch in keltischen Oppida nördlich der Alpen», Hamhurger Beitr: =. Arch. 4, 171-181.

JfFFERY, L. H., 1990: The Local Scripts of Archaic Greece, revised ed. w. suppl. by A. W. Johnston, Oxford.

KRÄMt:R. W., 1982: "Graffiti auf Spätlatėnekeramik aus Manching", Germania 60, 489-499.

LIII:UNI, M.. 1983: "Rencontres de l'alphabet grec avec les langues barbares au cours du I." millénaire av, J.-C.n, Modes de contact, 731-53.

2. : 1991: "Ambigüités du texte de Pech-Maho», REG 104, 311-29.

LEJEUNi, M., J. POUILLOUX \& Y. SOLIFR: 1988 (=1990): Étrusque et ionien archaïques sur un plomb de Pech Maho (Aude)", RAN 21, 19-59.

LtwIS, I., 1986: "Literacy and cultural identity in the Horn of Africa: the Somali case», G. Baumann ed., The Written Word, 113-149.

Llobrtiat, E., 1972: Contestania Ibérica, Alicante, (inscripciones en págs. 117-131).

- : 1989: "Los "graffiti" en escritura grecoibérica y púnica de la Illeta dels Banyets, El Campello (Alicante)", $A P L$ 19, 149-166

Maluquer de Montes, J., 1968: Epigrafia prelatina de la Peninsula Ihérica, Barcelona.

Marseille grecque et la Gaule, 1992: Etudes Massaliètes 3, Lattes.

MCKITTERICK, R. ed., 1990: The uses of literacy in early mediaeval Europe, Cambridge.

MezQuiriz, M."A., 1991-1992: "Pavimento de "Opus signinum" con inscripción ibérica en Andelos», Trabajos de Arqueologia en Navarra 10, 365-367.

_ : 1992: «Inscripción ibérica en Andelos (Mendigorria, Navarra)», Estudios... E. Pla, 347-349.

MichelenA, L., 1979: «La langue ibère», Actas II, 23-39 (= 1985: Lengua 341-356).

-: 1985: Lengua e historia, Madrid.

$\mathrm{MLH}=$ Untermann, $1975 \ldots$... Monumenta .

Modes de contacts et processus de transformation dans les sociétés anciennes, 1983: Pisa-Roma.

MORFNA, J. A., 1989: El santuario ibérico de Torreparedones (Castro del Rio-Baena. Córdoba), Córdoba.

MuÑoz, A. M., 1990: «Plomo ibérico en escritura griega de Coimbra del Barranco Ancho (Jumilla, Murcia)», Verdolay 2, 97-100.

Oppenheim, A. L., 1964: Ancient Mesopotamia. Portrait of a Dead Civilization, Chicago \& London.

Otero, J. M. \& Melena, J. L., 1976: "La estela inscrita de Siruela, Badajoz», Actas I lenguas y culturas, 343-352.

PANOSA, Má. I., 1993: «Complejidad, distribución y escritura en el NE peninsular. Hipótesis de trabajo», Actas V Coloquio, 719-725.

PARreira, R., 1993: «Espaço e Tempo: ocupaçao do solo no Alentejo e Algarve, entre o Neolítico e a Idade do Ferro", Dactiloscrito de conferencia en la "Casa de Velázquez» (16 de Febrero), Madrid.

Pellicer, M., 1979-1980: «Ensayo de periodización y cronología tartesia y turdetana», Habis 10-11, 307-333.

- : 1992: "Aproximación a la esencia de Tartessos», Andalusien zwischen Vorgeschichte und Mittelalter, herausg. v. D. Hertel \& J. Untermann, Köln, 29-73.

_. : 1993: "Crítica analítica de la arqueología tartesia y turdetana», Actas V Coloquio, 189-207.

Phoinikeia Grammata, 1991: Actes du Colloque de Liège, 15-18 noiembre 1989, édités par Cl. Baurain -C. Bonnet- V. Krings, Liège-Namur.

Roma y las primeras culturas epigráficas del Occidente mediterráneo, en prensa: ed. por F. Beltrán, Zaragoza.

Rouillard, P., 1991: Les Grecs et la Péninsule Ibérique du VIII' siècle au IV siècle avant JéusChrist, Paris.

RUiz Delgado, M. M., 1989: «Las necrópolis tartésicas: prestigio, poder y jerarquías», M. E. Aubet ed., Tartessos, 247-286. 
SANMARTi-Gri:Go, E.. 1988 ( = 1990): «Una carta en lengua ibérica, escrita sobre plomo, procedente de Emporion", R.AN 21, 95-113.

-: 1992: «Massalia et Emporion: une origine commune, deux destins différents», Marseille grecque et la Gaule, 27-41.

SANmARTi-Grigio, E. \& SAntiago, R. A., 1988 (=1990): «La lettre grecque d'Emporion et son contexte archéologique», RAN 21,3-17.

DA Silva, A. C. F. \& Gomes, M. V., 1992: Proto-Historia de Portugal, Lisboa.

TORI:LLI, M., 1990 (= 1981): Storia degli etruschi, Roma-Bari.

TRIAS, G., 1967-68: Cerámicas griegas de la Peninsula Ibérica I-II, Valencia.

UNTERMANN, J., 1969: "Lengua ibérica y lengua gala en la Galia Narbonensis», APL. 12, 99-161.

-: 1975/1980/1990: Monumenta Linguarum hispanicarum. I. Die Münzlegenden. II. Inschriften in iberischer Schrift aus Südfrankreich. III. Die iberischen Inschriften aus Spanien, Wiesbaden.

- : 1980: «Hispania», en Die Sprachen im römischen Reich der Kaiserszeit. Beiheft der Bonner Jahrbücher 40, 1-17. Köln.

—: 1983: «Die althispanischen Sprachen», ANRW II 29.2, Berlin, 791-818.

- 1983: «Die Keltiberer und das Keltiberische», E. Campanile ed., Problemi di lingua e di cultura nel campo indoeuropeo, Pisa, 109-127.

- : 1985: «Lenguas y unidades políticas del Suroeste hispánico en época prerromana», págs. 1-40 de Ch. Wentzlaff-Eggebert ed., De Tartessos a Cervantes, Köln-Wien.

-: 1987: "La gramática de los plomos ibéricos", Actas IV, 35-36.

- : en prensa: "La escritura tartesia entre Griegos y Fenicios, y lo que nos enseña el "alfabeto" de Espanca».

Vicente, J. D., M.* P. Punter, C. Escriche \& A. I. Herct, 1993: "La inscripción de la "Casa de LIKINE" (Caminreal, Teruel)", Actas del V Coloquio, 747-772.

ZELLER, K. W., 1988: «Neue keltischer Gewerbebauten auf den Dürrnberg bei Hallein», Salzburg Archiv 6, 5-22. 